\title{
BMJ Open Epidemiology and temporal trend of suicide mortality in the elderly in Jiading, Shanghai, 2003-2013: a descriptive, observational study
}

Yueqin Shao, ${ }^{1}$ Chenghua Zhu, ${ }^{2}$ Yiying Zhang, ${ }^{1}$ Hongjie Yu, ${ }^{1}$ Hui Peng, ${ }^{1}$
Yaqing Jin, ${ }^{1}$ Guozheng Shi, ${ }^{1}$ Na Wang, ${ }^{2}$ Zheng Chen, ${ }^{1}$ Yue Chen, ${ }^{3}$ Qingwu Jiang ${ }^{2}$

To cite: Shao Y, Zhu C, Zhang $Y$, et al. Epidemiology and temporal trend of suicide mortality in the elderly in Jiading, Shanghai, 20032013: a descriptive, observational study. BMJ Open 2016;6:e012227. doi:10.1136/bmjopen-2016012227

- Prepublication history for this paper is available online. To view these files please visit the journal online (http://dx.doi.org/10.1136/ bmjopen-2016-012227).

YS and CZ contributed equally.

Received 9 April 2016 Revised 17 July 2016 Accepted 19 July 2016

CrossMark

For numbered affiliations see end of article.

Correspondence to Dr Na Wang; na.wang@ fudan.edu.cn

\section{ABSTRACT}

Objectives: To investigate and describe the epidemiological characteristics of suicide in the elderly in Jiading, Shanghai, for the period 2003-2013.

Design: Retrospective, observational, epidemiological study using routinely collected data.

Setting: Jiading District, Shanghai.

Methods: Suicide data were retrieved from the Shanghai Vital Registry database for the period 20032013. Crude and age-standardised mortality rates were calculated for various groups according to sex and age. Joinpoint regression was performed to estimate the percentage change $(\mathrm{PC})$ and annual percentage change (APC) for suicide mortality.

Result: A total of 956 deaths due to suicide occurred among people aged $\geq 65$ years during the study period, accounting for $76.7 \%$ (956/1247) of all suicide decedents. Among the 956 people with suicide deaths, $88.7 \%$ (848/956) had a history of a psychiatric condition. The age-standardised mortality rates for suicide without and with a psychotic history in people aged $\geq 65$ years were much higher than those for people aged $<65$ years in both genders. Suicide mortality in the elderly showed a declining trend, with a PC of $-51.5 \%$ for men and $-47.5 \%$ for women. The APC was -29.1 in 2003-2005, 4.6 in 2005-2008 and -9.7 in 2008-2013 for aged men, and -12.2 in 2003-2006 and -5.2 in 2006-2013 for aged women, respectively. Women living in Jiading had a higher risk of suicide death than men, especially among the elderly. The mortality rate for suicide increased with age in the elderly, and was more marked for those with a psychiatric history than for those without.

Conclusions: Suicide mortality declined in Jiading during the study period 2003-2013 overall, but remained high in the elderly, especially those with a psychiatric history.

\section{INTRODUCTION}

In 2012, 8.04 million people died from suicide, accounting for $1.4 \%$ of the total deaths worldwide, and suicide was the 15th

\section{Strengths and limitations of this study}

- This study describes the epidemiology of suicide mortality for elderly people with and without a psychiatric history. To date, there has been limited research into the effect of psychiatric history on suicide death in the elderly.

- The data were retrieved from the Shanghai Vital Registry database and focused on the population from a suburban area in the process of urbanisation.

- The main limitations of the study are the lack of detailed information on the type and severity of psychiatric disease and information about suicide attempts.

leading cause of death. ${ }^{1}$ According to data from the Chinese Center for Disease Control and Prevention, suicide was the second leading cause of injury death for the general population, while death from all types of injury was the fourth most common cause of death after cardiovascular diseases, cancer and respiratory diseases. ${ }^{2}$

Suicide is a serious public health problem for the elderly, who constitute the greatest demographic group and have the highest suicide mortality in most countries. ${ }^{1}$ In developed countries, elderly men are at higher risk than elderly women, ${ }^{3}$ but the gender disparity is less pronounced in developing countries. ${ }^{4}$ Psychiatric illness is present in most suicide deaths in the elderly $(71-97 \%)$, with affective disorders being the most common. ${ }^{3}$

In the past two decades, overall suicide mortality has decreased remarkably in China, which might partly be due to the improvement in healthcare system and economic development. ${ }^{5}$ Suicide mortality shows some changing patterns, including a reduced discrepancy between urban and rural residents and an increased male/female ratio. ${ }^{6}$ The impact of psychiatric history on suicide 
mortality and gender difference has not been well investigated in the elderly, and the suicide mortality rate data based on complete surveillance are limited. ${ }^{5}$ With populations ageing and rapid urbanisation together with lifestyle changes, suicide mortality in the elderly is an important public health problem in China. This study examines the temporal trend and epidemiological characteristics of suicide mortality, especially among the elderly.

\section{METHODS AND MATERIALS \\ Data}

Jiading is a suburban district located in northwest Shanghai, with a revenue of 66 billion Chinese yuan in 2014. Of the total population of 5.76 million in 2014, 4.94 million were living in urban areas and the male/ female ratio was 0.99 . In this study, we used data extracted from the Shanghai Jiading Vital Registry database, which were provided by the Jiading District Center for Disease Control and Prevention, Shanghai. The causes of death were coded using the 10th edition of the International Classification of Diseases (ICD-10). Deaths for suicide were coded under external causes of morbidity, labelled V00-Y99. ${ }^{7}$ Suicide decedents were all registered permanent residents whose underlying cause of death was 'suicide'. Information was also obtained about comorbidities, including psychiatric disorders, which had been previously diagnosed by physicians and recorded on death certificates. All cases of suicide death were then divided into two groups: suicide deaths in people without and with a psychiatric history. We obtained demographical data of the general population from the Jiading Public Security Department. All private information including ID was blinded before conducting data analysis to meet the requirements of ethic statements. The study was approved by the ethical review board of the School of Public Health of Fudan University.

\section{Data analysis}

The study population was separated into two age groups ( $<65$ and $\geq 65$ years). For each of these two groups, we calculated the crude and age-standardised mortality rates for external causes, suicide and suicide without and with psychiatric history, respectively. To describe change over time, the percentage change (PC) was calculated using the following formula:

$$
\mathrm{PC} \%=\frac{\left(\mathrm{r}_{x}+\mathrm{r}_{x-1}\right)-\left(\mathrm{r}_{1}+\mathrm{r}_{2}\right)}{\left(\mathrm{r}_{1}+\mathrm{r}_{2}\right)} \times 100 \%
$$

where $r_{1}$ and $r_{2}$ are the first and second year's age-standardised mortality rates; $r_{x}$ and $r_{x-1}$ are the last and next to last year's age-standardised mortality rates, respectively.

We also analysed change over time using Joinpoint Trend Analysis Software, which was initially used by the

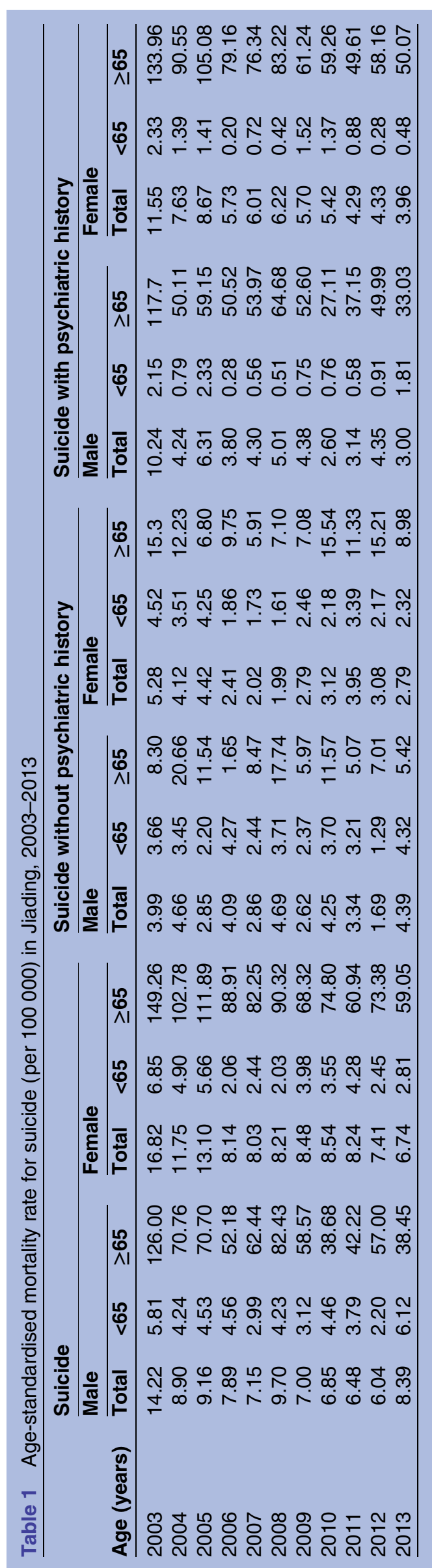


Table 2 PC and APC for suicide mortality in Jiading, 2003-2013

\begin{tabular}{|c|c|c|c|c|c|c|}
\hline & \multicolumn{3}{|l|}{ Male } & \multicolumn{3}{|l|}{ Female } \\
\hline & Total & $<65$ & $\geq 65$ & Total & $<65$ & $\geq 65$ \\
\hline $\begin{array}{l}\text { PC (\%) } \\
\text { APC (\%) }\end{array}$ & $\begin{array}{l}-37.6 \\
-4.9,-0.4,2.0\end{array}$ & $\begin{array}{l}-17.2 \\
-4.8^{\star}, 66.8\end{array}$ & $\begin{array}{l}-51.5 \\
-29.1,4.6,-9.7\end{array}$ & $\begin{array}{l}-50.5 \\
-2.0,0.8,-0.5\end{array}$ & $\begin{array}{l}-55.2 \\
-26.7^{\star}, 25.7,-16.7\end{array}$ & $\begin{array}{l}-47.5 \\
-12.2^{*},-5.2^{*}\end{array}$ \\
\hline
\end{tabular}

${ }^{\star}$ The APC is significantly different from 0 at $\alpha=0.05$.

APC, annual percentage change; PC, percentage change.

National Cancer Institute to analyse cancer trends and has been widely used in research into suicide. ${ }^{89}$

Briefly, the joinpoint regression analysis is fitted to a log-linear regression model and uses a Monte Carlo permutation method to test whether an apparent change in trend is statistically significant. ${ }^{8} 9$ The analysis starts with the minimum number of joinpoints (usually 0 joinpoint, which is a straight line) and tests whether one or more joinpoints are statistically significant and should be added to the model (up to the maximum number supplied by the user). Finally, age-standardised mortality rate, annual percentage change (APC) and its 95\% CI are estimated. The model can be expressed as follows:

$$
\ln (\text { rate })=\alpha+\beta(\text { year })+\varepsilon
$$

where $\alpha$ is a constant term; $\beta$ a regression coefficient and $\varepsilon$ an error term. APC can then be calculated as follows:

$$
\mathrm{APC} \%=100 \times\left(\mathrm{e}^{\beta}-1\right)
$$

APC is regarded as statistically significant when its $95 \%$ CI does not include zero. The joinpoint regression analysis was applied to raw mortality data according to sex, age and cause of death. Age-standardised mortality rates were calculated using the Segi World Standard Population. ${ }^{10}$

Excel and SAS, V.9.3 (SAS Institute, Inc, Cary, North Carolina, USA) were used for analysis and all tests of statistical significance were based on two-sided probability.

\section{RESULTS}

From 2003 to 2013, a total of 1247 deaths of suicide were identified, accounting for 26.9\% (1247/4639) of all-cause deaths and $40.3 \%$ (1247/3091) of deaths from external causes. Among all suicide decedents, people aged $\geq 65$ years accounted for $76.7 \%$ (956/1247). Among the 956 people with suicide deaths, $88.7 \%$ (848/ 956) had a history of a psychiatric condition.

The average mortality for suicide during 2003-2013 was $21.04 / 100000$. The average mortality rate for suicide was $4.30 / 100000$ for those aged $<65$ years and $16.12 / 100000$ for those aged $\geq 65$ years, respectively. The older age group had a higher crude mortality for suicide with psychiatric history than the younger group $(14.31 / 100000$ vs $1.19 / 100000)$, but the opposite was true for suicide without psychiatric history $(1.81 / 100000$ vs $3.10 / 100000)$. Elderly women had a higher crude mortality for suicide than elderly men $(21.88 / 100000$ vs $10.31 / 100000)$.

The overall age-standardised mortality for suicide declined from $14.22 / 100000$ in 2003 to $8.39 / 100000$ in 2013 in men, and from 16.82/100 000 to $6.74 / 100000$ in women. In comparison with people aged $<65$ years, those aged $\geq 65$ years, of both genders, had a higher suicide mortality, especially those with psychiatric history (table 1).

The PC for suicide mortality during 2003-2013 was $-37.6 \%$ for men and $-50.5 \%$ for women (tables 2 and $3)$. The suicide mortality decreased more rapidly in men aged $\geq 65$ years than men aged $<65$ years. The APC was statistically significant for decreasing suicide mortality for women aged $\geq 65$ years during the period from 2003 to 2011 and for men aged $<65$ years during the period from 2003 to 2008 (figures 1-3).

The gender disparity in suicide mortality was greater in the elderly than in younger people. The male/female ratio in those aged $\geq 65$ years was $0.5 \quad\left(\chi^{2}=126.7\right.$, $\mathrm{p}<0.001)$ for overall suicide mortality and $0.4\left(\chi^{2}=126.9\right.$, $\mathrm{p}<0.001)$ for suicide mortality with a psychiatric history, while the corresponding ratios in those aged $<65$ years were $1.2\left(\chi^{2}=2.1, \mathrm{p}>0.05\right)$ and $1.1 \quad\left(\chi^{2}=0.1, \mathrm{p}>0.05\right)$, respectively. The mortality rate for suicide without a history of psychiatric illness overall showed no gender difference $\left(\mathrm{M} / \mathrm{F}\right.$ ratio $\left.1.01\left(\chi^{2}=0.013, \mathrm{p}>0.05\right)\right)$.

The age-specific suicide mortality without a psychiatric history showed no substantial change with age, whereas the suicide mortality with psychiatric history increased after 65 years of age (figure 4 ).

\section{DISCUSSION}

Our study observed a decreasing suicide mortality rate during the period from 2003 to 2013 in a rural-urban fringe district in Shanghai. Elderly people comprised the greatest proportion of suicide deaths in Jiading district. Suicide decedents in the elderly were mostly female, especially for suicide deaths in those people with a psychiatric history. Suicide with psychiatric history mostly occurred in people aged $\geq 65$ years, while suicide without psychiatric history mostly in people aged $<65$ years.

Suicide is a serious public health problem, occurring at all ages. Suicide is the second leading cause of death in youth and young adults globally, whereas suicide 


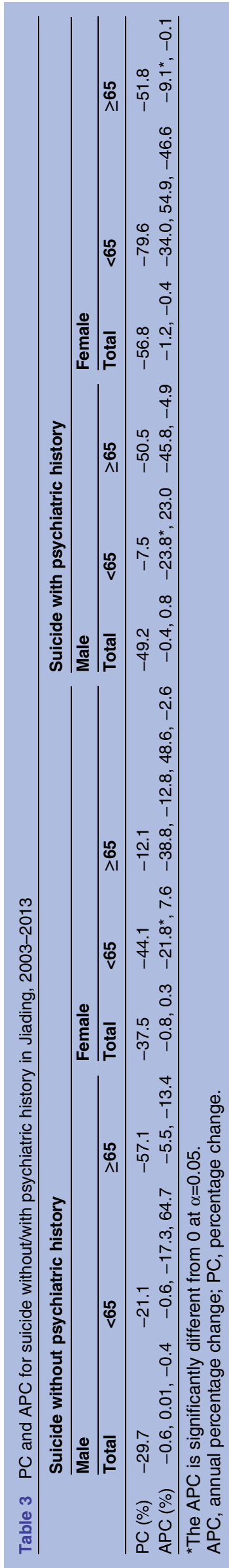

mortality is the highest in people aged $\geq 70$ years for both genders in almost all regions of the world. ${ }^{189} 91112$ Similar findings have also been documented in China. Studies of Suzhou city, ${ }^{13}$ Chengdu city, ${ }^{14}$ Harbin province $^{15}$ and the whole nation ${ }^{6}$ all indicated an increase in suicide mortality with age in adults. One study from Shandong province noticed that suicide risk for people aged $\geq 65$ years was five times greater than in the general population. ${ }^{16}$ Previous studies in Shanghai ${ }^{17}$ have also shown a similar trend with a slightly lower mortality rate of $15.99 / 100000$ in the elderly than that of Jiading district (16.12/100 000) in our study. Reasons are complicated. Suicide ideation and suicide attempts in older adults were strongly associated with disability, activity limitation and extreme pain. ${ }^{18}$ Other reasons include the presence of physical or mental disorders, ${ }^{19}{ }^{20}$ poor function of self-care,${ }^{21}$ lower levels of education, ${ }^{22}$ higher rate of unemployment ${ }^{23}$ and living alone. $^{24}$

The gender difference in suicide mortality in China has changed over the past few decades. One study, based on data from the China vital registration system for the period 1995-1999, found that the mortality rate was higher in women than in men, mainly due to death in young rural women. ${ }^{25}$ Another study, based on data from the Chinese Health Statistics Year Books of 20022011, noted that the suicide mortality rate in men exceeded that in women after 2006, and proposed that the change in women's social position might be a reason. ${ }^{6}$ Being a rural-urban fringe district, Jiading district has a male predominance in people aged $<65$ years and a female predominance in people aged $\geq 65$ years. This gender difference in the elderly might be due to different status of social support or social connectedness, which is associated with suicidal ideation and suicide in later life. ${ }^{26}$ Research has suggested that social factors, such as negative life events and social support, might have more significant roles in suicidality in Asia than the West. ${ }^{27}$ Another study, conducted in Jiading district, showed a lower score on an objective support subscale, subjective support scale, utility degree of social support and the total scores of social support in Jiading compared with the national norm, and a significantly lower social support score in women than men. ${ }^{28}$ These factors might underlie the predominance of suicide in elderly women in Jiading. Moreover, the difference in suicide method ${ }^{29}$ or the strain theory ${ }^{30}$ may explain the gender difference in younger people.

Among all the suicide deaths in Jiading, $74.7 \%$ were in people with a psychiatric history, which was higher than in a previous study in China $(62.9 \%) .{ }^{31}$ The corresponding proportion was even higher in the elderly $(88.7 \%)$. Having a mental disorder was the most important determinant of suicidality in older adults. ${ }^{22}$ Insomnia, ${ }^{32}$ major depressive episodes, ${ }^{33}$ dysthymia ${ }^{34}$ and many other disorders are associated with thought of suicide or attempts. With ageing of the population, the number of elderly people with mental disorders has 

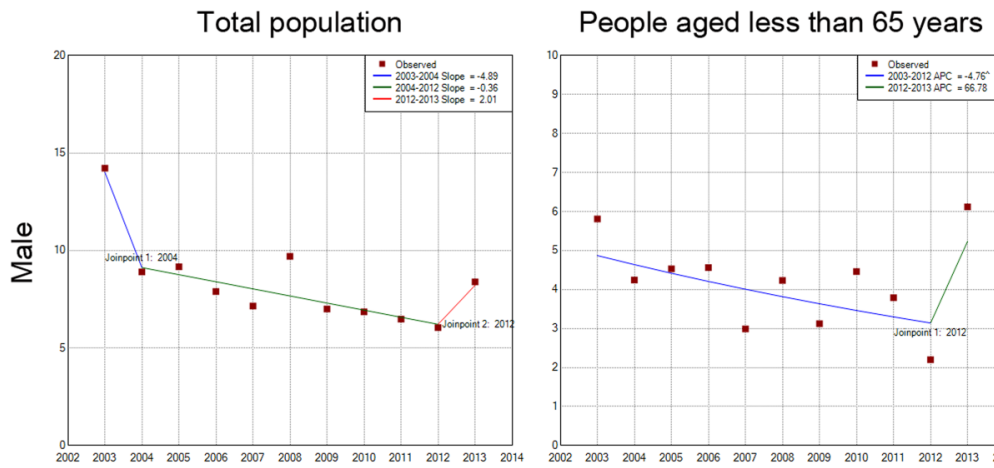

People aged more than 65 years
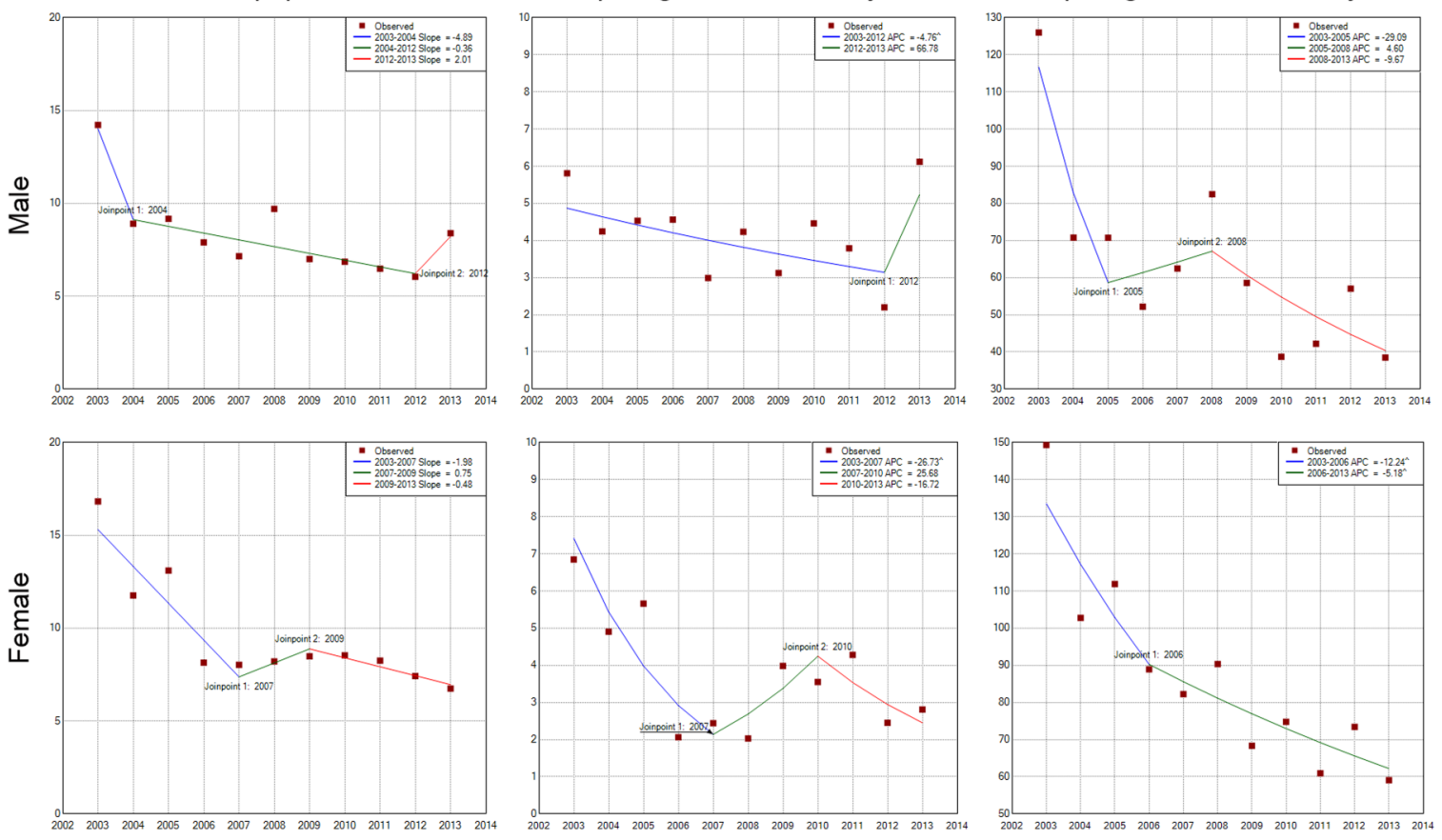

Figure 1 Joinpoint regression analysis of suicide mortality for men and women in Jiading, 2003-2013.
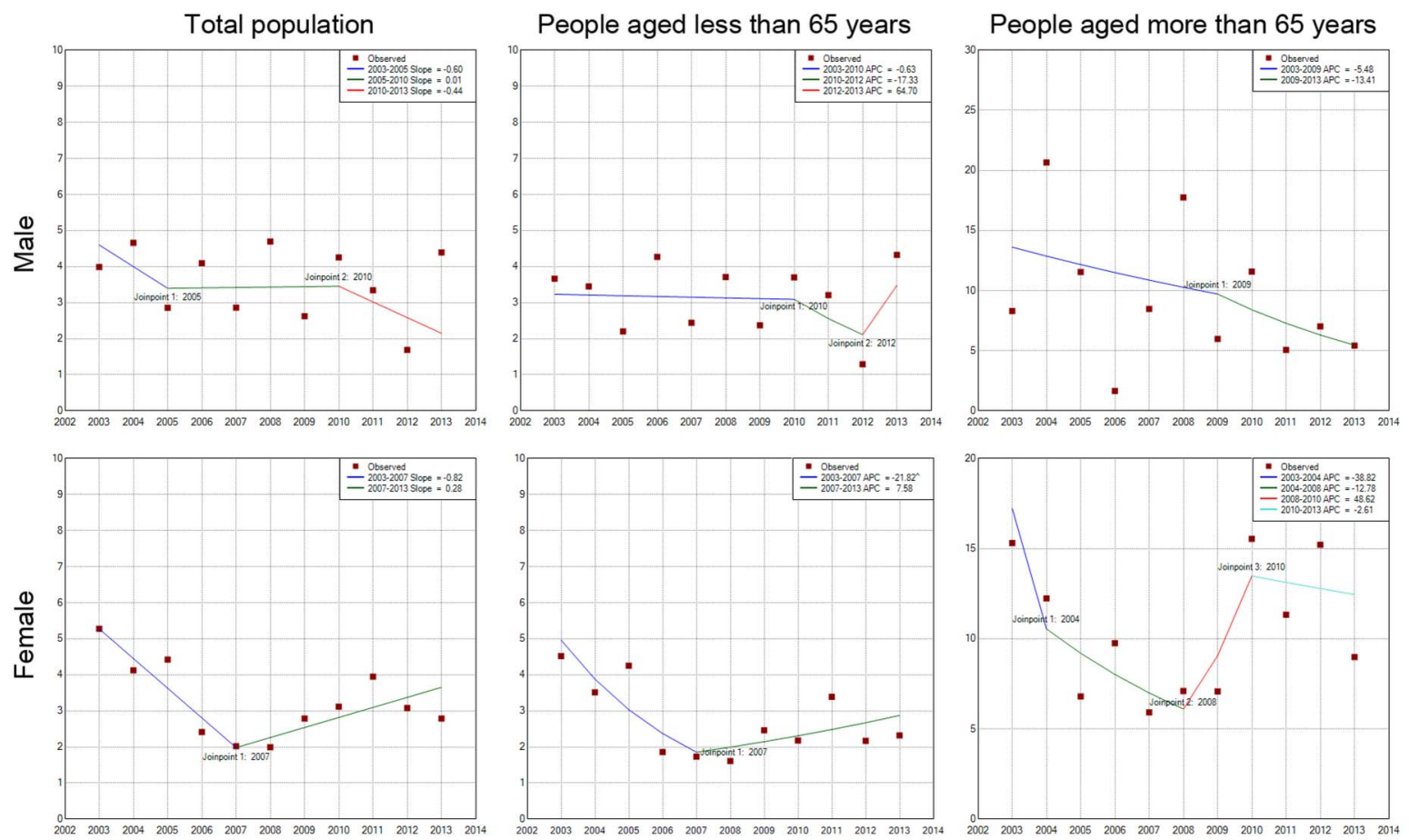

Figure 2 Joinpoint regression analysis of suicide mortality for men and women without psychiatric history in Jiading, 20032013.

increased significantly. Being in a rapid process of urbanisation, Jiading district might have more empty nesters and elderly people living alone without connection with family. Family connectedness is a strong protective factor against suicide ideation in the elderly, and a key component in the intervention and treatment of mental illness. ${ }^{35}$ However, ageing does not appear to modify the relationship between depressive symptoms and suicide behaviour. ${ }^{36}$ Distinctive prevention strategies should be developed and adopted in two age groups ${ }^{37}$ such as interventions to avoid loneliness and lack of social support status in the elderly ${ }^{38}$ and treatment of mental health conditions in the general population. ${ }^{39}$ 

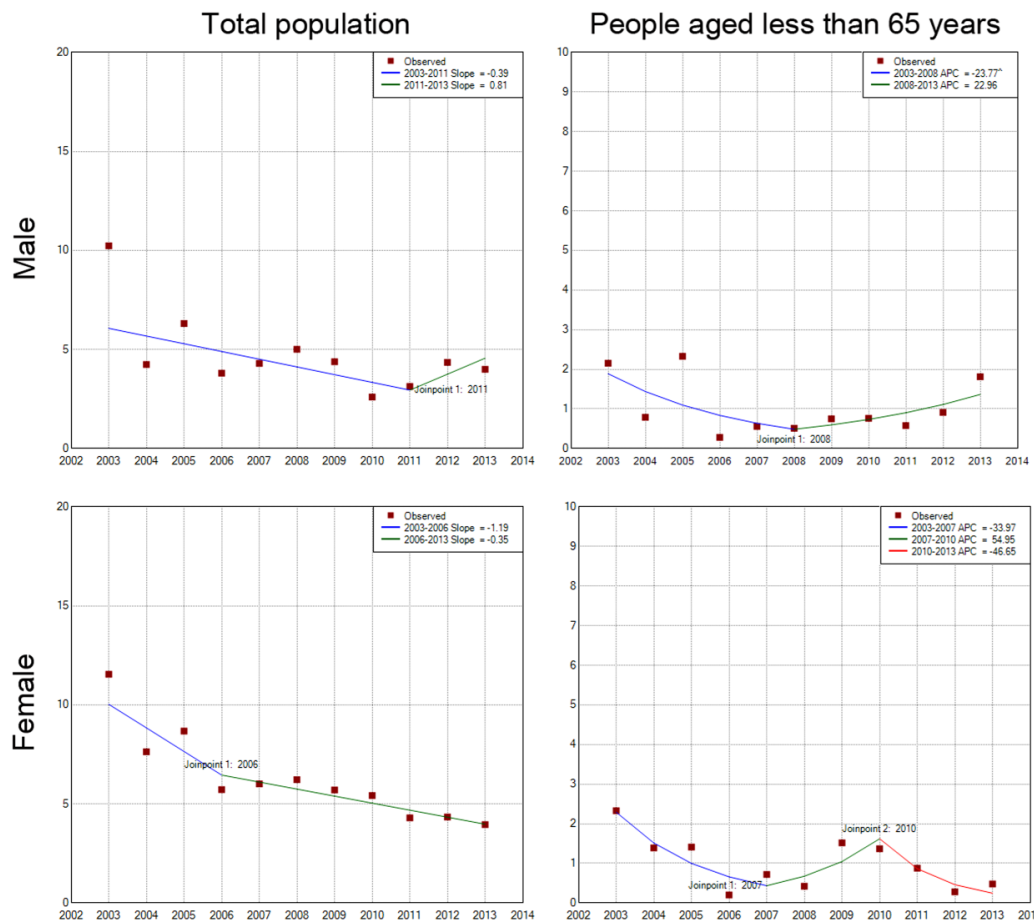

People aged less than 65 years

People aged more than 65 years
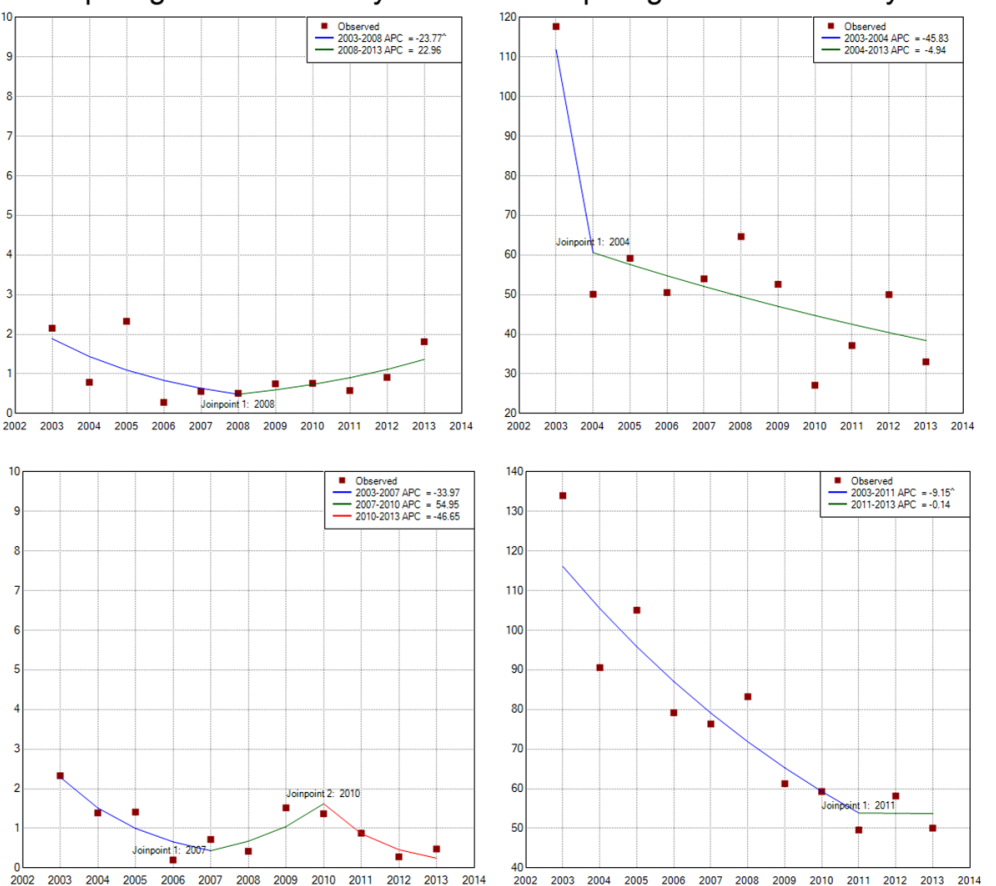

Figure 3 Joinpoint regression analysis of suicide mortality for men and women with psychiatric history in Jiading, 2003-2013.

Figure 4 Age-specific mortality (per 100 000) for suicide and for suicide without/with psychiatric history in Jiading, 2003-2013.

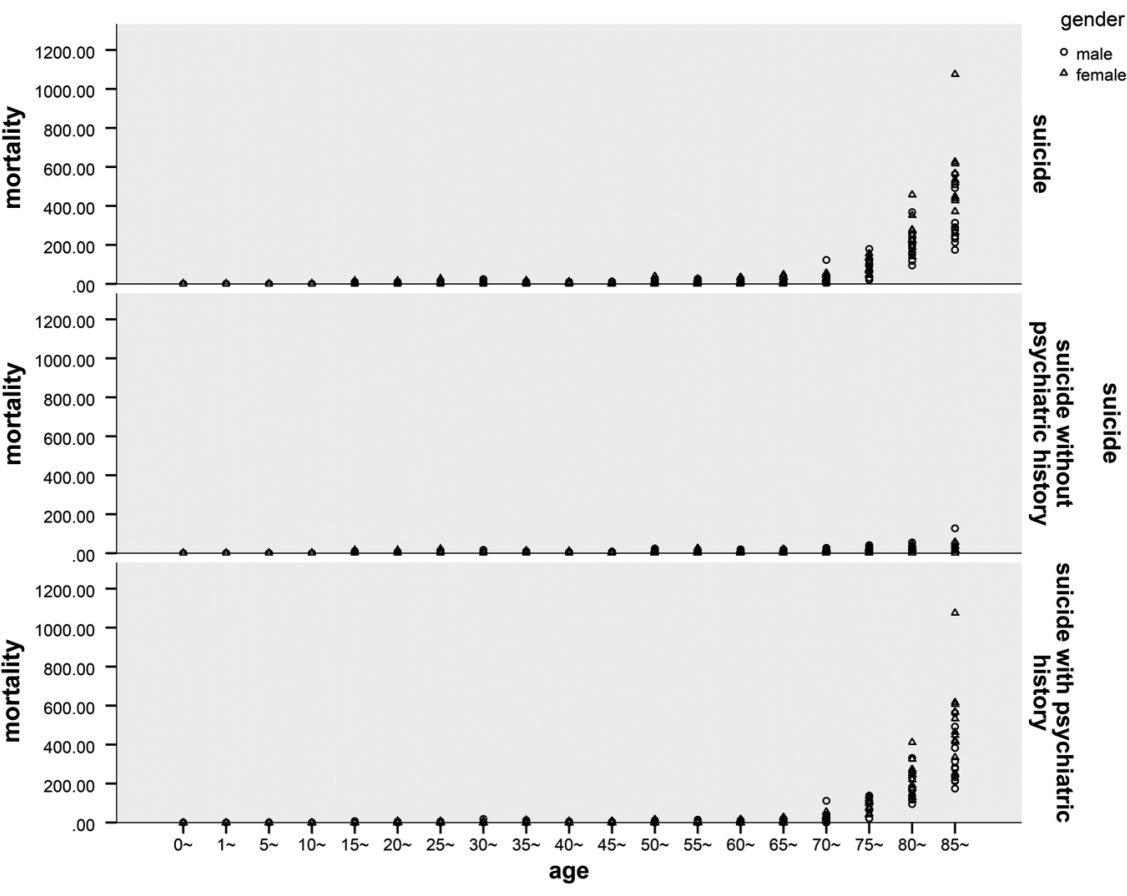

\section{Limitations}

Our study has several limitations. We did not have the information on the suicide attempts of this population and could not compare the characteristics of suicide and suicide-attempt groups. Second, since the information on psychiatric disorders of suicide decedents was provided by their relatives, this might have led to an underestimation of this comorbidity. In addition, we assumed that suicide deaths were classified accurately. However, there is evidence that other forms of death might have been misclassified as suicide, although this occurs infrequently.

\section{CONCLUSION}

Suicide mortality in the elderly varied and showed a declining trend during the period 2003-2013 in Jiading district. The trend was more pronounced in the elderly for those with a psychiatric history than for those without such a history. However, the mortality rate remained relatively high for the study period. 
Author affiliations

${ }^{1}$ Jiading District Center for Disease Control and Prevention, Shanghai, China

${ }^{2}$ Key Laboratory of Public Health Safety of Ministry of Education, School of

Public Health, Fudan University, Shanghai, China

${ }^{3}$ Faculty of Medicine, School of Epidemiology, Public Health, and Preventive

Medicine, University of Ottawa, Ottawa, Ontario, Canada

Contributors CZ, YS and NW contributed to the study concept and design; all authors contributed to data acquisition and collection; CZ, YS, NW and YC contributed to data analysis and interpretation; $\mathrm{CZ}$, NW and $\mathrm{YC}$ drafted the manuscript; all authors contributed to revision of the manuscript, read and approved the final manuscript.

Funding The study was supported by the Shanghai Key Discipline Construction Project of Shanghai Municipal Public Health (grant no. 15GWZK0801).

Competing interests None declared.

Provenance and peer review Not commissioned; externally peer reviewed.

Data sharing statement No additional data are available.

Open Access This is an Open Access article distributed in accordance with the Creative Commons Attribution Non Commercial (CC BY-NC 4.0) license, which permits others to distribute, remix, adapt, build upon this work noncommercially, and license their derivative works on different terms, provided the original work is properly cited and the use is non-commercial. See: http:// creativecommons.org/licenses/by-nc/4.0/

\section{REFERENCES}

1. WHO. Preventing suicide: a global imperative. World Health Organization, 2014.

2. Cai Y, Hu N, Liu Y, et al. Suicide analysis of Chinese population in 2010. Zhonghua Yu Fang Yi Xue Za Zhi 2012;13:480-2.

3. Conwell Y, Van Orden K, Caine ED. Suicide in older adults. Psychiatr Clin North Am 2011;34:451-68.

4. Hendin $\mathrm{H}$, Phillips MR, Vijayakumar L, et al. Suicide and suicide prevention in Asia. Mental health and substance abuse. World Health Organization, 2008.

5. Yip PSF, Liu KY, Hu J, et al. Suicide rates in China during a decade of rapid social changes. Soc Psychiatry Psychiatr Epidemiol 2005;40:792-8.

6. Zhang J, Sun L, Liu Y, et al. The change in suicide rates between 2002 and 2011 in China. Suicide Life Threat Behav 2014;44:560-8.

7. ICD-10-CM Tabular list of diseases and injuries 2016. http://apps. who.int/classifications/icd10/browse/2016/en

8. Vichi M, Masocco M, Pompili M, et al. Suicide mortality in Italy from 1980 to 2002. Psychiatry Res 2010;175:89-97.

9. Bando DH, Brunoni AR, Fernandes TG, et al. Suicide rates and trends in São Paulo, Brazil, according to gender, age and demographic aspects: a joinpoint regression analysis. Rev Bras Psiquiatr 2012;34:286-93.

10. Doll R, Payne P, Waterhouse J. Cancer incidence in five continents. Springer-Verlag Berlin Heidelberg, 1966.

11. Qi X, Hu W, Page A, et al. Dynamic pattern of suicide in Australia, 1986-2005: a descriptive-analytic study. BMJ Open 2014;4: e005311-e11.

12. Lovisi GM, Santos SA, Legay L, et al. Epidemiological analysis of suicide in Brazil from 1980 to 2006. Rev Bras Psiquiatr 2009;31 (Suppl 2):S86-94.

13. Lu Y, Wang L. Analysis on the epidemiological charateristics of the suicide data of residents in Suzhou from 2003 to 2012. Chin J Prev Control Chron Dis 2014;22:448-50.

14. Peng Z, Feng X, Liao J, et al. Suicide of residents in Chengdu, 2006-2010. J Prev Med Info 2013;29:383-5.

15. Lan L, Sui C, Xu G, et al. Analysis on suicide mortality among city's population in Harbin from 1988 to 2009. Chin J Public Health Manag 2011(02):196-7.
16. Sun J, Guo X, Zhang J, et al. Suicide rates in Shandong, China, 1991-2010: rapid decrease in rural rates and steady increase in male-female ratio. $J$ Affect Disord 2013;146:361-8.

17. Wei X, Yu Z, Yisheng W. Epidemiological analysis on suicide among Zhabei residents, 1995-2004. Chin J Dis Control Prev 2006;10:48-50.

18. Kim SH. Suicidal ideation and suicide attempts in older adults: influences of chronic illness, functional limitations, and pain. Geriatr Nurs 2016;37:9-12.

19. Erlangsen A, Stenager E, Conwell Y. Physical diseases as predictors of suicide in older adults: a nationwide, register-based cohort study. Soc Psychiatry Psychiatr Epidemiol 2015;50:1427-39.

20. Ruckenbauer G, Yazdani F, Ravaglia G. Suicide in old age: illness or autonomous decision of the will? Arch Gerontol Geriatr 2007:44:355-8.

21. Tsoh J, Chiu HFK, Duberstein PR, et al. Attempted suicide in elderly Chinese persons: a multi-group, controlled study. Am J Geriatr Psychiatry 2005;13:562-71.

22. Ngamini Ngui A, Vasiliadis HM, Préville M. Individual and area-level factors correlated with death by suicide in older adults. Prev Med 2015;75:44-8

23. Wiktorsson S, Runeson B, Skoog I, et al. Attempted suicide in the elderly: characteristics of suicide attempters 70 years and older and a general population comparison group. Am J Geriatr Psychiatry 2010;18:57-67.

24. Purcell B, Heisel MJ, Speice J, et al. Family connectedness moderates the association between living alone. Am J Geriatr Psychiatry 2012;20:717-23.

25. Phillips MR, Li X, Zhang Y. Suicide rates in China, 1995-99. Lancet 2002;359:835-40.

26. Fässberg MM, Orden KAV, Duberstein P, et al. A systematic review of social factors and suicidal behavior in older adulthood. Int J Environ Res Public Health 2012;9:722-45.

27. Park S, Hatim Sulaiman A, Srisurapanont $M$, et al. The association of suicide risk with negative life events and social support according to gender in Asian patients with major depressive disorder. Psychiatry Res 2015;228:277-82.

28. Zhao J, Zhao X, Liu H, et al. Study on social support status and influencing factors among community-based elderly residents in Jiading, Shanghai. Chin J Health Educ 2015;31:11-14, 27.

29. Callanan VJ, Davis MS. Gender differences in suicide methods. Soc Psychiatry Psychiatr Epidemiol 2012;47:857-69.

30. Zhang J, Wieczorek WF, Conwell Y, et al. Psychological strains and youth suicide in rural China. Soc Sci Med 2011;72: 2003-10.

31. Yang GH, Phililips MR, Zhou MG, et al. Understanding the unique characteristics of suicide in China: national psychological autopsy study. Biomed Environ Sci 2005;18:379.

32. Hung GC-L, Kwok C-L, Yip PSF, et al. Predicting suicide in older adults-a community-based cohort study in Taipei City, Taiwan. $J$ Affect Disord 2015;172:165-70.

33. Miret M, Ayuso-Mateos JL, Sanchez-Moreno J, et al. Depressive disorders and suicide: epidemiology, risk factors, and burden. Neurosci Biobehav Rev 2013;37:2372-4.

34. Bernal M, Haro JM, Bernert S, et al. Risk factors for suicidality in Europe: results from the ESEMED study. J Affect Disord 2007;101:27-34.

35. Lask J. Family and psychiatric illness: family therapy. In: Wright J, ed. International encyclopedia of the social \& behavioral sciences (second edition). Oxford: Elsevier, 2015:745-50.

36. Harvey PD, Czaja SJ, Loewenstein DA. Schizophrenia in later life. Am J Geriatr Psychiatry 2012;20:1-4.

37. Hawton K, van Heeringen K. Suicide. Lancet 2009;373:1372-81.

38. Innamorati M, Pompili M, Di Vittorio C, et al. Suicide in the old elderly: results from one Italian county. Am J Geriatr Psychiatry 2014:22:1158-67.

39. Raposo S, El-Gabalawy R, Erickson J, et al. Associations between anxiety disorders, suicide ideation, and age in nationally representative samples of Canadian and American adults. $J$ Anxiety Disord 2014;28:823-9. 